\title{
STORYNOMICS BALI AGA: PEMANFAATAN CERITA RAKYAT UNTUK PROMOSI DESA WISATA SIDETAPA, KABUPATEN BULELENG
}

\author{
Ida Ayu Laksmita Sari \\ Universitas Udayana \\ Email: dayumita23@gmail.com \\ I Nyoman Darma Putra \\ Universitas Udayana \\ Email: idarmaputra@yahoo.com \\ Ni Luh Ramaswati Purnawan \\ Universitas Udayana \\ Email: ramaswati.purnawan@unud.ac.id \\ I Wayan Suardiana \\ Universitas Udayana \\ Email: i.suardiana@yahoo.co.id
}

\begin{abstract}
Stories about tourist attractions can add dimensions to the quality of the attraction and the tourist experience. This article analyzes the benefits of folklore in improving the quality of tourist attractions in Sidetapa Tourism Village, Banjar District, Buleleng Regency. The village, which is classified as an ancient Balinese village, has begun to develop itself as a tourist village and has a tourist attraction related to the village's folklore. This qualitative research begins with identifying folklore and selecting those related to tourist attractions in Sidetapa Village. By using the storynomics approach, the selected stories are then arranged in two forms, namely the complete form and the concise form. This story is prepared for tourism-awareness groups that can be used as material in guiding tours. This article contributes to showing the reciprocal benefits of folklore and tourist attraction, in terms of the role of folklore to increase the dimensions of the quality of tourist attraction and the benefits of tourism activities in preserving folklore by introducing them to the public and tourists.
\end{abstract}

Keywords: folklore, storynomics, Sidetapa Tourism Village, tourist attraction, tourist experience. 


\section{Pendahuluan}

Di tengah drastisnya dampak buruk pandemi Covid-19 terhadap bisnis dan aktivitas kepariwisataan (Anggarini, 2021; Sugihamretha, 2020), pemerintah Indonesia tetap menunjukkan semangat untuk membangun industri jasa pariwisata, bahkan sebagai salah satu prioritas pembangunan. Semangat membangun pariwisata Indonesia itu dilakukan pemerintah dalam dua arus utama, yaitu pembangunan pariwisata superprioritas yang terintegrasi dengan modal besar; dan pembangunan desa wisata yang bersifat massif dengan modal kecil di seluruh Indonesia (Putra, Adnyani, Munarti 2021; Wiranatha et. al., 2021).

Pembangunan destinasi wisata superprioritas dilaksanakan dengan modal ratusan milyar bahkan mencapai satu dua trilyun untuk satu kawasan dilakukan untuk kawasan Danau Toba, Borobudur, Resort Wisata Mandalika, Labuan Bajo/ Komodo, dan Likupang di Sulawesi Utara (Bima, Jofari, \& Chandra, 2020). Untuk pembangunan desa wisata, pemerintah melakukan banyak program bimbingan teknis dan penganugerahan desa wisata. Selain itu, pemerintah mengizinkan dana desa yang disalurkan pemerintah untuk digunakan membangun fasilitas kepariwisataan. Di Bali, pulau yang kecil ini, terdapat 179 desa wisata, sebagian besar tumbuh karena dorongan dari pemerintah dan pengesahan berdasarkan surat keputusan bupati. Beberapa desa lainnya yang tidak ditetapkan sebagai desa wisata dengan SK Bupati/ Walikota tetap berkembang sebagai daya tarik wisata seperti Desa Kutuh dengan Pantai Pandawa dan Desa Ungasan dengan Pantai Melasti yang sangat terkenal dan dikunjungan banyak wisatawan, terutama sebelum pandemi. Di kabupaten-kabupaten di Bali, juga muncul banyak desa menjadi desa wisata, termasuk Desa Wisata Sidetapa di Kabupaten Buleleng.

Bersama 25 desa lainnya, Desa Sidetapa di Kecamatan Banjar ditetapkan oleh Pemerintah Kabupaten Buleleng sebagai desa wisata pada tahun 2017 melalui SK No 430/405/HK/2017 (Widiastini et.al, 2020:305). Sejak itu, Desa Sidetapa dan empat desa 
Bali Kuna lainnya yaitu Cempaga, Tigawasa, Pedawa, dan Banyuseri (disingkat SCTPB) sama-sama berada di wilayah Kecamatan Banjar aktif mengembangkan potensi sebagai daya tarik wisata (Andini \& Pujaastawa, 2018; Andiani, 2020). Namun demikian, usaha-usaha mereka menghadapi sejumlah kendala, mulai dari kesiapan SDM, belum tumbuhnya kesadaran hospitality, kendala menambah daya tarik wisata, serta kekurangsiapan mempromosikannya (Widiastini \& Rahmawati, 2020).

Artikel ini berkaitan dengan usaha membantu Desa Wisata Sidetapa dalam melakukan promosi pariwisata untuk mencapai setidaknya tiga tujuan berikut: (1) Sidetapa lebih dikenal masyarakat, khususnya calon wisatawan sehingga mereka tertarik untuk datang; (2) Memberikan pengalaman berlibur berkualitas kepada wisatawan sehingga mereka tertarik untuk datang lagi ke Sidetapa; (3) Wisatawan yang merasakan kepuasan dalam berlibur di Sidetapa dapat mempromosikan Desa Sidetapa secara sukarela lewat berbagai bentuk dan media termasuk sosial media.

Bentuk promosi yang bisa dilaksanakan untuk sebuah destinasi wisata, termasuk desa wisata, beragam adanya. Dalam artikel ini, bentuk promosi diarahkan pada usaha meningkatkan pengalaman wisatawan berwisata di Desa Wisata Sidetapa dengan menyuguhkan mereka cerita informatif dan unik yang berkaitan dengan daya tarik wisata di Sidetapa. Dengan menuturkan apa yang dilihat wisatawan, para wisatawan akan memiliki pengetahuan yang lebih dalam tentang desa ini. Pengetahuan tentang yang dilihat itu dapat meningkatkan kepuasan dan pengalaman berlibur wisatawan (tourist experience).

Secara spesifik dalam konteks peningkatan pengalaman berwisata dan promosi sukarela dari wisatawan, artikel ini mengkaji kontribusi tradisi lisan berupa cerita rakyat Bali Aga dalam mendukung perkembangan pariwisata Sidetapa melalui program yang dikenal dengan storynomics, yaitu memanfaatkan cerita untuk mendapat keuntungan ekonomi (McKee dan Gerace, 2018). Wisatawan yang berkunjung ke Sidetapa tidak akan merasa puas hanya dengan melihat apa yang 
nyata, tetapi juga mengenal cerita di balik kenyataan itu. Hal ini bertolak dari provosisi bahwa setiap hal, barang, dan bangunan pasti memiliki cerita. Dengan menuturkan cerita sebuah daya tarik wisata, wisatawan akan mendapat pengetahuan yang lebih lengkap, gabungan antara tatapan visual dan cerapan narasi. Sementara kenyataan bisa diabadikan lewat kamera, narasi tentang kenyataan itu bisa diabadikan dalam ingatan atau memori. Ingatan inilah yang mudah diproduksi untuk promosi atau dituturkan kepada orang lain sehingga tertarik untuk datang.

Kajian dalam artikel ini dimaksudkan memberikan kontribusi dalam pengembangan khususnya peningkatan kualitas day atarik wisata Desa Sidetapa dalam dua hal. Pertama, pemanfaatan potensi lokal berupa cerita rakyat untuk informasi sekaligus daya tarik wisata di Sidetapa. Kedua, menyediakan bentuk ringkas (simplified form) dari cerita rakyat atau tradisi lisan Sidetapa sehingga bisa digunakan oleh pemadu wisata atau kelompok sadar wisata dalam mengantar tamu atau memberikan keterangan kepada para wisatawan yang berkunjung ke Sidetapa. Artikel ini merupakan hasil dari program pengabdian pada masyarakat di Desa Sidetapa dengan tema storynomic yang tujuannya adalah menggali, memilih, dan menyiapkan cerita rakyat atau tradisi lisan yang merupakan bagian dari cultural heritage (warisan budaya) sebagai pendukung pengembangan pariwisata Sidetapa.

\section{Kajian Pustaka}

Penelitian terhadap desa wisata secara umum sudah banyak dilakukan para peneliti, demikian juga halnya dengan desa wisata-desa wisata di kawasan Bali Aga, Bali Utara, di mana Sidetapa termasuk salah satu di antaranya. Kajian tentang Desa Wisata Sidetapa dan desa-desa Bali Aga dalam kelompok yang dikenal dengan SCTPB (Sidetapa, Cempaga, Tigawasa, Pedawa, Banyusri) menarik para ahli karena desa-desa ini merupakan desa tua yang memiliki keunikan seni budaya dan sejarah (Simpen 1986; Sari 2019; Sari dan Putra 2020). Ada juga kajian tentang sistem kepercayaan masyarakat SCTPB khususnya Sidetapa yang dilakukan Gata dalam 
artikelnya "Filosofis Sampradaya Dalam Kehidupan Sosial Masyarakat Hindu di Bali (Studi Kasus di Desa Sidatapa, Kabupaten Buleleng) (2020). Kajian yang berkaitan dengan agama dan tradisi di SCTPB terus bermunculan sejalan dengan hadirnya peneliti-peneliti mahasiswa dan dosen muda di Bali Utara yang pelan-pelan tetapi pasti menjadikan desa-desa Bali Aga sebagai laboratorium riset mereka yang dekat jaraknya.

Keunikan budaya yang dimiliki desa-desa SCTPB menjadi potensi dasar pengembangan pariwisata. Karena keunikannya, selain aspek adat dan budayanya, mulai muncul kajian aspek pariwisata. Beberapa kajian terhadap pariwisata Sidetapa diarahkan untuk meniliti berbagai aspek Desa Wisata Sidetapa. Kelompok peneliti yang perlu disebutkan banyak melakukan riset di desa ini adalah Widiastini dkk dari Universitas Pendidikan Ganesha Singaraja, dengan beberapa riset dan publikasi termasuk "Preparing Sidatapa Village as a Bali Aga Tourist Attraction in Buleleng Regency” (2020), “Preparing Guest Room for Tourists in Sidetapa Village, Buleleng, Bali" (2021), dan Pendampingan Pengemasan Produk Brem Buah Desa Sidatapa, Kabupaten Buleleng (2020a). Semua kajian ini memberikan fokus pada Desa Sidetata. Seperti tercermin di judul, penelitian Widiastini dan timnya mengkaji topik penyiapan daya tarik wisata, akomodasi, dan produk brem buah. Dua yang pertama berkaitan dengan atraksi dan amenities, yang ketiga berkaitan dengan suvenir atau oleh-oleh produksi lokal, salah satu unsur dari Sapta Pesona.

Ketiga penelitian ini memiliki tujuan yang jelas yaitu pemberdayaan Desa Sidetapa dalam menyiapkan diri sebagai destinasi wisata yang memiliki daya tarik dan fasilitas yang menambah magnetnya untuk membujuk wisatawan untung datang. Kelengkapan akomodasi dan kesiapan daya tarik adalah untuk esensial sebuah destinasi wisata. Dilihat dari konsep sapta pesona bahwa sebuah destinasi wisata perlu menyediakan suvenir bagi wisatawan, hal ini tampak dipenuhi oleh Sidetapa [kadang ditulis Sidatapa] dengan menyediakan minuman brem. Pengemasan terhadap produk buah ini tidak saja menyajikan produk lokal bernilai 
jual tetapi juga pelestarian kearifan lokal dalam memproduksi brem. Dengan pariwisata, kearifan lokal ini diharapkan juga berkembang dan memberikan manfaat ekonomi karena produknya bisa dijual, seperti ditulis oleh Widiastini et. al (2020a) berikut.

Produk brem hasil produksi masyarakat Desa Sidatapa yang telah mulai dijual lebih luas, telah mendapat respon yang baik. Sebagai hasil produksi masyarakat lokal, produk brem dianggap mampu membentuk desa wisata yang mereka bangun, dimana mereka pada akhirnya diharapkan mampu memiliki produk wisata unggulan sebagai cenderamata bagi wisatawan. Dalam hal ini, brand sebuah desa juga akan terbangun sehingga dapat menjadi pembeda dengan desa wisata lainnya di Kabupaten Buleleng (2020a:1108-1109).

Selain itu, Widiastini juga membahas secara umum pengembangan desa wisata di Kabupaten Buleleng dan mengikutsertakan Sidetapa sebagai bahan kajian, seperti bisa disimak dalam artikelnya "Ragam Branding Desa dalam Mengembangkan Potensi Wisata Berbasis Budaya Masyarakat di Kabupaten Buleleng" (Widiastini et. al. 2020a). Dalam kajian ini, Widiastini menyampaikan:

Sebagai desa tua yang memiliki kekhasan tradisi yang unik dan berbeda dengan desa lainnya, Desa Sembiran, Desa Julah, Desa Sidatapa, dan Desa Pedawa, begitu juga desa tua lainnya di Kabupaten Buleleng yakni Desa Tigawasa, Desa Cempaga dan Desa Banyuseri mampu membentuk brand sebagai destinasi wisata melalui citranya sebagai desa tua. Namun, tentu dalam perkembangannya, segala tradisi yang ada harus tetap mampu dipertahankan agar citra yang dibentuk dapat menjadi ikon destinasi yang berkelanjutan (2020a: 203-204).

Dalam tulisan ini, Widiastini et. al mengeaskan keberhasil desa-desa Bali Aga termasuk Sidetapa dalam menciptakan branding melalui modal budayanya sebagai desa tua.

Dari penelitian-penelitian yang ada, belum ada kajian khusus mengenai pemanfaatan kekayaan tradisi lisan atau cerita rakyat Sidetapa dalam memperkuat branding sebagai desa tua. Topik ini merupakan gap yang dijawab dalam artikel ini, 
yakni secara khusus mengangkat cerita rakyat untuk dijadikan pelengkap daya tarik wisata yang dapat memperkuat branding Sidetapa sebagai desa tua.

\section{Metode dan Teori}

Kajian ini merupakan kajian kualitatif yang datanya berasal dari program pengabdian masyarakat dengan skema Program Udayana untuk Masyarakat (PUMA) yang dialksanakan tahun 2021. Dalam penelitian ini, proses kerja berkaitan dengan penggalian cerita rakyat dan pemilihan yang relevan untuk dikemas menjadi storynomics, untuk dipakai oleh kelompok sadar wisata (pokdarwis) setempat untuk dituturkan kepada wisatawan. Pengumpulan data dengan wawancara untuk tahap awal, identifikasi cerita rakyat dan DTW dilakukan di Desa Sidetapa sebanyak tujuh kali kali, yaitu pada bulan Juni dan Juli 2021 untuk mengumpulkan bahan mengenai cerita-cerita rakyat yang berpotensi menjadi literasi storynomics yang bisa dikaitkan dengan DTW yang potensial. Wawancara dilakukan dengan tokoh masyarakat sekaligus mitra yaitu Ketua Bali Aga Harmoni, Wayan Aryawan dan juga tokoh masyarakat yang memiliki pengetahuan mengenai cerita rakyat asli Desa Sidetapa, atau yang memahami konteks yang berkaitan budaya, tradisi, dan pariwisata.

Cerita rakyat yang sudah dikumpulkan ditulis sesuai dengan isi cerita dalam dua bentuk, yaitu versi lengkap (panjang) dan versi ringkas (simplified form). Anggota Pokdarwis diharapkan mengenal keduanya, walau dalam kegiatan wisata yang diperlukan adalah bentuk ringkas karena wisatawan tidak memiliki banyak waktu untuk mendengarkan cerita panjang. Susunan cerita bentuk panjang dan ringkas itu yang merupakan hasil dari penelitian ini dan dalam artikel ini dianalisis isi cerita dan relevansinya dengan daya atrik wisata yang ada dan keterkaitannya dengan aktivitas wisata yang bisa diikuti wisatawan. 
Teori utama yang digunakan dalam analisis ini adalah storynomics yang diambil dari buku Robets McKee dan Thomas Gerace yang berjudul Storynomics: Story-Driven Marketing in the Post-Advertising World (2018). Dalam buku ini, McKee dan Gerace menegaskan bahwa Storynomics "to title the story-centric business practice that drive fiscal result" ('Storynomics digunakan untuk memberi nama pada praktik dagang yang menggunakan cerita untuk mendapatkan hasil uang') (McKee, 2018:12). Dengan menyiapkan cerita yang menarik, proses pemasaran menjadi berbeda. Sebuah produk yang memiliki nilai cerita dapat digunakan untuk membujuk calon pembeli mengambil keputusan pembelian. Mckee juga mengatakan bahwa konsep storynomics adalah menyusun cerita, dibutuhkan tahapan yang teratur dan terencana sehingga cerita tersebut dapat memukau pendengar atau pembaca (Mckee, 2018:53).

Penggunaan storynomics untuk promosi daerah wisata atau untuk meningkatkan kualitas pengalaman wisatawan saat berkunjung ke daya tarik wisata sudah mulai muncul di Indonesia. Kajian untuk itu pun mulai bermunculan. Contohnya bisa dilihat dari kajian Kartini berjudul "Analisis SWOT terhadap Storynomics Tourism sebagai Strategi Promosi Pariwisata (Studi Kasus Kawasan Wisata Kali Cisadane, Kota Tangerang, Banten, Indonesia) (2021), Sukmadewi dalam artikel “Storynomics Tourism: Kualitas Wisata Desa Tenganan Pegringsingan” (2021), dan Kartika, T., \& Riana, N. dalam artikel "Storynomics Tourism as an Effective Marketing Strategy on Tourism Destination (Case Study on Tangkuban Parahu, West Java-Indonesia) (2020). Ketiganya menjadikan storynomics sebagai tema utama kajiannya. Kajian mereka membuka cakrawala baru kajian cerita rakyat dengan daya tarik wisata. Dalam konteks daya tarik wisata Tangkuban Perahu di Jawa Barat, Kartika dan Riana menyampaikan manfaat cerita rakyat setempat sebagai berikut:

The folklore of Sangkuriang, which is strong among the people, has become one of the attractions of tourists, especially from domestic. The strength of folklore and other supporting aspects and its relation to storynomics can be used as an effective marketing strategy for the Tangkuban Parahu destination (2020:39). 
artinya

Cerita rakyat Sangkuriang yang terkenal luas di kalangan masyarakat menjadi salah satu daya tarik wisatawan terutama wisatawan dari dalam negeri. Kekuatan cerita rakyat dan aspek pendukung lainnya serta kaitannya dengan storynomics dapat dijadikan sebagai strategi pemasaran yang efektif untuk destinasi Tangkuban Parahu.

Dalam kutipan di atas ditegaskan bawah kekuatan cerita Sangkuriang menambah magnet atau daya tarik Gunung Tangkuban Perahu. Kontribusi cerita rakyat ikut memberikan kekuatan daya tarik wisata. Wisatawan tertarik mengunjungi Tangkuban Perahu antara lain karena mendengar cerita rakyat Sangkuriang dan setelah mereka ke sana mereka menjadikan cerita rakyat Sangkuriang sebagai bahan promosi dari mulut ke mulut (words of mouth). Manfaat cerita rakyat untuk mendukung daya tarik wisata sudah lama terjadi, tetapi kajian-kajian terhadapnya merupakan kecenderungan baru.

\section{Hasil dan Pembahasan}

Daya tarik wisata Sidetapa bisa dibedakan menjadi dua, yaitu wisata alam dan budaya. Untuk wisata alam contohnya adalah alam perdesaan yang terletak di perbukitan dengan lanskap yang indah, air terjun Yeh Mampah, batu raksasa, trekking, dan hutan kera (monkey forest). Daya tarik budaya, misalnya seni tari untuk ritual di desa, arsitektur rumah kuna (bale gajah tumpang salu), tradisi menganyam bamboo, aktivitas membuat gula aren sebagai bagian integral dari kehidupan seharihari di desa. Walaupun potensi begitu besar, Desa Sidetapa masih menghadapi beberapa kendala dalam perkembangan pariwisata.

Sama dengan desa-desa SCTPB, Desa Sidetapa juga kaya akan cerita, mitos legenda yang berkaitan dengan tradisi, sistem kepercayaan, arsitektur, dan juga yang berkaitan dengan tempat. Tradisi yang masih dilaksanakan sampai sekarang dan tempat yang memiliki cerita dapat dijadikan daya tarik wisata, seperti halnya daya 
tarik wisata Tangkuban Perahu di Jawa Barat (Kartika \& Riana, 2020) dan daya tarik wisata Mandalika di Lombok (Suyasa, 2020). Dengan demikian, penggalian storynomics akan menambah jumlah daya tarik wisata. Untuk daya tarik wisata yang sudah ada dan ditawarkan, storynomics dapat meningkatkan kualitas pengalaman menikmati daya tarik wisata tersebut.

Di Sidetapa terdapat air terjun Yeh Mampah yang dapat diperkenalkan atau ditata menjadi daya tarik wisata. Daya tarik wisata air terjun Yeh Mampah ini terdapat cerita "Asal Usul Desa Sidetapa" yang mengisahkan bagaimana air di Yeh Mampah tersebut menjadi air suci untuk upacara. Mungkin ada beberapa versi mengenai cerita air terjun tersebut, tetapi yang jelas, penyediaan storynomics air terjun yang semula belum banyak orang yang mengetahuinya kini menjadi penguat promosi air terjun tersebut, apalagi daya tari alam air terjun ini akan ditata untuk dijadikan daya tarik wisata unggulan. Air terjun ini terletak 1,5 km dari pusat desa. Lanskap alamnya sangat indah dengan daya tarik utama air terjun yang mengusur dalam ketinggian 40 meter.

Begitu juga halnya dengan cerita mengenai rumah kuna Sidetapa yaitu bale gajah tumpang salu. Ada beberapa cerita yang dikaitkan dengan rumah ini, terutama karena rumah ini menghadap ke dalam dan di dalamnya ada ruangan yang dipisahkan menjadi tiga sesuai fungsinya: pemujaan, tempat tingal, dan dapur. Secara arsitektural dan bahan baku, rumah ini menarik karena dibuat dari tanah polpolan, sebuah teknologi pembuatan rumah tempat tinggal. Bahwa rumah menghadap ke dalam, itu dikaitkan dengan mitos Mayadenawa, raja yang dianggap melarang orang bersembahyang untuk menyembah Tuhan kecuali dirinya. Menolak ancaman Mayadenawa dan agar masyarakat tetap dapat melaksanakan kewajiban akan tradisi dan kepercayaannya, mereka melakukan persembahyang secara sembunyi-sembunyi di dalam rumah menghadap ke dalam, tidak terlihat dari luar (andaikan Mayadenawa lewat). Keunikan struktur bale gajah tumpang salu ini adalah di dalamnya terdapat 
ruang dapur, tidur, dan bersembahyang. Struktur seperti ini tipikal rumah ada di Asia Tenggara, seperti terlihat juga di rumah ada Sumba dan Flores.

Di Sidetapa ada banyak rumah kuna, dalam pendataan belum lama ini diketahui ada sekitar 130-an rumah. Akan tetapi, salah satu rumah yang layak dikunjungi adalah milik Wayan Ariawan, perintis tokoh Bali Aga Harmoni. Ini berarti sebagian besar rumah kuna masyarakat kurang dirawat. Kalau nanti wisatawan kian tertarik akan arsitektur kuna, berarti masyarakat akan terdorong dan perlu didorong untuk melestarikan rumah kuna mereka. Perubahan memang tidak terhindarkan, termasuk karena alasan keuangan dan bahan baku. Dewasa ini, semakin banyak rumah kuna menggunakan atap seng, dari dulu biasanya alang-alang.

Dalam penelitian yang berbasis program pengabdian ini dicari lima cerita rakyat atau tradisi lisan untuk dijadikan storynomics, yaitu cerita atau narasi yang terkait dengan objek alam atau budaya yang sudah atau dapat dijadikan daya tarik wisata (DTW). Kelima cerita itu, inti nrasi, dan kaitannya dengan objek ayng menjadi daya tarik dituangkan dalam Tabel 1.

Tabel 1. Daftar Cerita Rakyat Sidetapa untuk Storynomic

\begin{tabular}{|c|c|c|c|}
\hline No. & $\begin{array}{l}\text { Judul } \\
\text { Cerita }\end{array}$ & $\begin{array}{c}\text { Relevansi } \\
\text { dengan Daya } \\
\text { Tarik }\end{array}$ & Keterangan \\
\hline 1. & $\begin{array}{l}\text { Bale Gajah } \\
\text { Tumpang } \\
\text { Salu }\end{array}$ & $\begin{array}{l}\text { Mitos } \\
\text { Mayadenawa } \\
\text { dalam sistem } \\
\text { kepercayaan }\end{array}$ & $\begin{array}{l}\text {-Bale Tumpang Salu sudah menjadi daya } \\
\text { tarik wisata (DTW) tetapi jumlahnya } \\
\text { terbatas, kurang tertata } \\
\text {-Perlu pelestarian, dampakya menjadi } \\
\text { DTW yang menarik } \\
\text {-Pelestarian diawali dengan pengenalan } \\
\text { lewat narasi baik kepada warga maupun } \\
\text { kepada wisatawan }\end{array}$ \\
\hline 2. & $\begin{array}{l}\text { Puniki } \\
\text { Katuturan } \\
\text { Kawitan }\end{array}$ & $\begin{array}{l}\text { Air Terjun Yeh } \\
\text { Mampah hanya } \\
1,5 \mathrm{~km} \text { dari pusat }\end{array}$ & $\begin{array}{l}\text {-DTW unggul belum ditata, akan ramai jika } \\
\text { dipromosikan }\end{array}$ \\
\hline
\end{tabular}




\begin{tabular}{|c|c|c|c|}
\hline & $\begin{array}{l}\text { Desa } \\
\text { Sidetapa }\end{array}$ & $\begin{array}{l}\text { desa, air terjun } \\
\text { dengan } \\
\text { ketinggian } 40 \\
\text { meter }\end{array}$ & $\begin{array}{l}\text {-Memerlukan infrastruktur akses dan } \\
\text { fasilitas mandi } \\
\text {-Daya tarik lanskap alam indah akan } \\
\text { menjadi lengkap dengan mitos dari cerita } \\
\text { rakyat }\end{array}$ \\
\hline 3. & Sinayu & Gastronomi lokal & $\begin{array}{l}\text {-Memasak lauk sinayu bisa dijadikan } \\
\text { bagian cooking class, bentuk aktivitas wisata } \\
\text { yang populer belakangan ini } \\
\text {-Cerita tentang sinayu bisa menjadi narasi } \\
\text { penting untuk mempromosikan } \\
\text { gastronomi lokal Sidetapa }\end{array}$ \\
\hline 4. & I Cucu & $\begin{array}{l}\text { Gastronomi lokal } \\
\text { Keahlian } \\
\text { menangkap } \\
\text { buruan dengan } \\
\text { cara tradisional }\end{array}$ & $\begin{array}{l}\text {-Palem udang dan timbungan, cara } \\
\text { memasak tradisional Bali Aga } \\
\text {-Bubu atau kerajinan lain dari bambu }\end{array}$ \\
\hline 5. & I Gancang & $\begin{array}{l}\text { Gastronomi lokal } \\
\text { Hari Raya } \\
\text { Galungan (Bali } \\
\text { Aga) }\end{array}$ & $\begin{array}{l}\text {-Cara mengawetkan makanan menjadi } \\
\text { dendeng } \\
\text {-Memperkenalkan hari Raya Galungan } \\
\text { adat Bali Aga }\end{array}$ \\
\hline
\end{tabular}

Kisah pertama yang diangkat sebagai storynomics dalam penelitian berbasis pengabdian ini adalah cerita berjudul "Bale Gajah Tumpang Salu". Kisah ini mengungkapkan mengapa rumah tradisional Desa Sidetapa menghadap belakang atau membelakangi jalan raya. Daya tarik wisata rumah kuna ini merupakan salah satu tempat favorit bagi wisatawan yang berkunjung ke Sidetapa karena masih dapat melihat rumah tradisional yang asli dan sangat unik. Kisah rumah ini bersifat fragmentaris, banyak versi tidak lengkap. Dalam penelitian ini, berdasarkan diskusi dan simak-periksa bersama tim pengabdi/ peneliti, mitra, dan beberapa tetua adat di Desa Sidepa berembug untuk menyepakati kisah yang akan ditulis sebagai cerita dalam buku ilustrasi. 
Sebelumnya, cerita tentang Bale Gajah Tumpang Salu ini juga diangkat berdasarkan beberapa keterangan narasumber, dan buku dari "Adat Kuna Catur Desa (Tiga Wasa, Sidatapa, Pedawa, Cempaga) karya W. Simpen A.B (1986), “Desa Tua di Bali Utara Kebanggaan Identitas Bali Aga (Sidatapa, Cempaga, Tigawasa, Pedawa) karya Arya Wedakarna, dkk. (2014), dan beberapa sumber tertulis lainnya. Mitos inti yang diketahui dari narasumber bahwa kisah mengapa rumah menghadap ke belakang ada kaitannya dengan mitos "Mayadenawa" dari masal silam yang melarang penduduk Bali, termasuk masyarakat Desa Sidetapa untuk menyembah Tuhan. Oleh karena itu, penduduk mengganti arah masuk ke rumah mereka menjadi masuk dari belakang, selain itu juga agar mereka bisa bersembahyang maka ada yang disebut "pepaga" yang diletakkan di dalam rumah sebagai sarana untuk berdoa serta mempersembahkan sesajen kepada Tuhan.

Wisatawan yang berkunjung ke Sidetapa tertarik melihat arsitektur bangunan kuna. Mereka pasti memiliki rasa ingin tahu dengan bertanya mengapa arsitektur ini demikian unik. Saat itulah, pemandu wisata bertugas menjelaskan, memenuhi rasa ingin tahu wisatawan. Kisah arsitektur, heritage, dan sosial budaya sudah teramu dalam cerita "Bale Gajah Tumpang Salu". Jika wisatawan tidak bertanya, tugas pemandu untuk menjelaskan atau memberikan highlight (penegasan) pada keunikan daya tarik arsitektur Sidetapa.

Sama dengan cerita "Bale Gajah Tumpang Salu”, cerita "Sinayu" juga menarik diangkat sebagai storynomics karena memiliki keunikan dan relevan dengan keseharian warga Sidetapa. Cerita ini merupakan teks naratif yang mengisahkan seluk-beluk mengolah serangga sinayu (serangga, juga dikenal dengan suara yang ditimbulkan yaitu 'cerèrèt') menjadi lauk-pauk. Dalam cerita ini dituturkan secara detail, metamorfosis sinayu dari ulat menjadi sinayu (sindet, bekukang, ayong-ayong) dan cara hidupnya. Setelah menjadi sinayu, serangga yang ukuran tubuhnya sebesar jari kelingking orang dewasa ini memiliki sayap dan bisa terbang. Saat menjadi ulat hidupnya di tanah, setelah menjadi sinayu hidupnya di pohon sure ('surian'). Cara 
menangkap sinayu juga dituturkan dalam cerita ini, yaitu dengan menggunakan getah atau menggosok pohon tempat hinggapnya, yaitu pohon sure dan saat berjatuhan mereka akan tertangkap oleh jaring yang dipasang di bawah. Sinayu berbiak saat bulan Maret/April setiap tahun. Keunikan ini bisa dikemas dalam narasi untuk storynomics mempromosikan tradisi budaya Sidetapa.

Di Sidetapa, banyak orang yang suka dengan lauk sinayu hingga dewasa ini. Cerita juga menuturkan cara mengolah masakan sinayu, seperti memasaknya menjadi lauk gerang dengan cara digoreng, bisa juga dengan cara dikukus, atau ditumbuk dengan uyah asemin ('garam dan asem'). Unsur naratif kisah ini tanpa alur (plot), tetapi jelas bahwa cerita ini menyajikan pengetahuan tradisional mengenai seluk-beluk sinayu dan cara memasaknya. Selain itu, cerita ini juga menunjukkan relevansi kearifan lokal dalam cerita rakyat terhadap kehidupan praktis dewasa ini.

Kelima cerita yang dipilih sebagai materi stoynomics dibuat dalam dua versi yaitu versi bahasa Indonesia dan versi bahasa Inggris, masing-masing dalma bentuk utuh dan bentuk ringkas (simplified form). Pembuatan dalam dua versi bahasa adalah untuk kepentingan wisatawan: tamu asing atau domestik. Selain untuk kepentingan promosi wisata, cerita ini juga dijadikan materi dalam kursus bahasa Inggris Sidetapa English Corner (SEC) yang diikuti anak-anak desa setempat. Dari bahan yang ada, anak-anak SEC dapat belajar bahasa Inggris dan juga dapat mengenal cerita rakyat desanya. Jika mereka ebrtemu wisatawan, mereka bisa menjelaskan sesuai versi yang ada.

Menurut tokoh pariwisata, I Wayan Ariawan, penggalian cerita rakyat untuk mendukung kualitas daya tarik wisata merupakan usaha baru yang menarik. Selama ini, potensi cerita rakayt dan potensi daya tarik wisata merupakan dua hal terpisah, sekarang ini, setelah adanya penelitian dari Universitas Udayana, ternyata keduanya bisa dimanfaatkan secara terintegrasi. Wayan Ariawan yang juga Ketua Bali Aga Harmoni, dalam wawancara (15 Juni 2021) menyampaikan: 
Pengabdian dan penelitian dari tim Universitas Udayana memberikan inspriasi baru bagi kami bahwa tradisi lisan yang kami miliki ternyata bisa dikemas menjadi storynomics untuk menambah kualitas daya tarik. Kualitas daya tarik ayng bertambah membuat pengalaman wisatawan berlibur di Desa kami menjadi lebih berkesan. Kami harap itu menjadi promosi yang baik yang akan dituturkan para wisatawan kepada teman atau kepada calon wisatawan lain.

Potensi tradisi lisan dan daya tarik wisata yang bisa disatukan itu akan berhasil membuat daya tarik desa wisata Sidetapa jika memang terus dikembangkan dan dirawat. Pengembangan daya tarik wisata lain seperti pembuatan brem, anyaman bambu, atau gula aren di Sidetapa atau desa Bali Aga lain di sekitarnya bisa diarahkan dengan melakukan penggalian pada tradisi lisan atau mitos-mitos yang berkaitan. Sebuah produk, seperti dikemukakan dalam buku Storynomics, dapat dijual dengan lebih mudah dan lebih menguntungkan jika disertai cerita atau mitos yang terkait dengannya. Potensi Sidetapa dan desa wisata di kawasan Bali Aga lainnya yang akan akan potensi daya tarik wisata dan cerita rakyat bisa dikolaborasikan untuk manfaat ganda yaitu memajukan industri pariwisata yang dapat menignkatkan perekonomian rakyat dan pelestarian tradisi budaya.

\section{Penutup}

Kekayaan tradisi lisan, cerita rakyat, atau mitos bisa diseleksi dan diangkat untuk mendukung daya tarik wisata. Dengan pendekatan storynomics, penelitian ini menggali sejumlah cerita rakyat sebagai storynomics yang dimanfaatkan secara speisifik sebagai berikut. Pertama, menjadi bahan bagi anggota pokdarwis atau pemandu wisata lokal untuk dituturkan kepada wisatawan sehingga wisatawan tidak saja melihat tetapi mengetahui cerita unik di balik daya tarik yang mereka kunjungi atau alami. Kedua, storynomics dapat dijadikan dasar untuk menggali dan menata daya tarik wisata baru yang berkaitan dengan cerita atau mitos. Ketiga, storynomics membantu melestarikan tradisi lisan dan kearifan lokal lewat teks tertulis. Keempat, 
storynomics dapat menjadi bahan pengayaan dalam program Sidetapa English Corner sehingga anak-anak atau SDM lokal mengetahui kekayaan cerita desanya dan mampu menyampaikan dalam bahasa Inggris.

Storynomics tidak hanya dapat dikaitkan dengan tempat wisata maupun gastronomi suatu daerah, namun dapat juga dikaitkan dengan hasil kerajinan. Jika sebuah suvenir yang dijual oleh masyarakat memiliki cerita di baliknya maka produk kerajinan itu dapat bertambah nilainya dan para wisatawan akan lebih mengingat daerah yang dikunjunginya karena cerita di balik produk yang dilihat atau dibeli.

Saran untuk pelaksana pengabdian pada masyarakat atau peneliti selanjutnya adalah memaksimalkan narasi maupun mitos yang terdapat di suatu daerah agar dapat menarasikan potensi suatu daerah dengan baik dengan tujuan akhir mendapatkan keuntungan ekonomi bagi masyarakat di daerah tersebut seperti rintisan di Desa Sidetapa.

\section{Ucapan Terima Kasih}

Artikel ini disusun berdasarkan hasil riset dalam kegiatan Program Udayana untuk Masyarakat (PUMA) yang didanai LPPM Universitas Udayana lewat DIPA PNBP Universitas Udayana TA-2021 Sesuai dengan Surat Perjanjian Penugasan Pelaksanaan Penelitian Nomor: B/100-34/UN14.4.AI/PM.01.03/2021, tanggal: 3 Mei 2021. Penulis menyampaikan terima kasih kepada Kepala LPPM Unud dan Rektor Universitas Udayana atas fasilitas yang disediakan.

\section{Daftar Pustaka}

Andini, N. D., \& Pujaastawa, I. G. 2018. Peran serta elit desa dalam pengembangan pariwisata di Desa Cempaga Kecamatan Banjar Kabupaten Buleleng Bali. Jurnal Humanis, 22(1), 87-95. 
Andiani, Nyoman Dini et al. 2020. “Peran Nilai Hindu “Tri Kaya Parisudha” dalam Peningkatan Loyalitas Wisatawan Terhadap Desa Wisata Pedawa, Bali Utara. Jurnal Kajian Bali (Journal of Bali Studies), Vol. 10, No. 2, pp. 603-624, Oktober.

Anggarini, D. T. (2021). Upaya pemulihan industri pariwisata dalam situasi pandemi Covid-19. Jurnal Pariwisata, 8(1), 22-31.

Bima, A. P., Jofari, H. A., \& Chandra, E. P. (2020). “Tantangan Indonesia Dalam Penataan Pariwisata Super Prioritas Dalam Persaingan Global", Prosiding Simposium Nasional"'Tantangan Penyelenggaraan Pemerintahan di Era Revolusi Indusri 4. O", 1551-1570.

Dewi, I. K., \& Fitriani, D. R. (2021). Storynomic as Marketing Strategy of Telaga Sarangan Magetan. International Journal of Educational Research E Social Sciences, 2(6), 1384-1393.

Gata, I. W. (2020). Filosofis Sampradaya Dalam Kehidupan Sosial Masyarakat Hindu di Bali (Studi Kasus di Desa Sidatapa, Kabupaten Buleleng). Genta Hredaya: Media Informasi Ilmiah Jurusan Brahma Widya STAHN Mpu Kuturan Singaraja, 2(1).

Hunter, Justine. 2012. "Tourism off Center: Ainu Ethnic Tourism a Identity Conctruction and Artistic Expression in Modern Japan", paper presented at $57^{\text {th }}$ Anuual of the Society for Ethnomusicology, Nov 3, 2012.

Kartika, T., \& Riana, N. (2020). Storynomics Tourism as an Effective Marketing Strategy on Tourism Destination (Case Study on Tangkuban Parahu, West Java-Indonesia). Tourism and Sustainable Development Review, 1(1), 33-40.

Kartini, R. A. (2021). “Analisis Swot Terhadap Storynomics Tourism Sebagai Strategi Promosi Pariwisata (Studi Kasus Kawasan Wisata Kali Cisadane, Kota Tangerang, Banten, Indonesia)". Dynamic Management Journal, 5(2), 58-69.

McKee, Robets dan Thomas Gerace. 2018. Storynomics: Story-Driven Marketing in the Post-Advertising World. UK: Grand Central publishing.

Mokoagow, F. N. (2021). Strategi storynomic tourism dalam akun instagram@ genpisulut sebagai upaya membangkitkan sektor pariwisata Sulawesi Utara di masa pandemi covid-19=@ genpisulut tourism storynomic strategy as an effort toenergy the North Sulawesi tourism sector in the time of covid-19 (Doctoral dissertation, Universitas Pelita Harapan).

Putra, K. A. (2021). Katalog Info Wisata Desa Wisata Sidetapa Kabupaten Buleleng (Doctoral dissertation, Universitas Pendidikan Ganesha).

Sari, I. A. L. (2020). Storynomics: Memanfaatkan Kekuatan Branding Cerita Rakyat. Prosiding ISBI Bandung, 1(1). 
Sari, I. A. L., \& Putra, I. N. D. Narrative on Nature Conservation: A Comparative Study of the Folktales of Bali Aga and Ainu. KEMANUSIAAN The Asian Journal of Humanities, 27(2), 59-78. https://doi.org/10.21315/KAJH2020.27.2.4

Sari, Ida Ayu Laksmita. 2019. “Kajian Komparatif Wacana Kearifan Lokal Cerita Rakyat Bali Aga dan Ainu Jepang", disertasi Prodi DOktor S-3 Linguistik, Fakultas Ilmu Budaya, Universitas Udayana.

Simpen AB, Wayan. 1986. “Catur Desa: Tigawsa, Sidatapa, Pedawa, Cempaga” dalam Laporan Penelitian Fakultas Sastra Universitas Udayana.

Sugihamretha, I. D. G. (2020). Respon Kebijakan: Mitigasi Dampak Wabah Covid-19 Pada Sektor Pariwisata. Jurnal Perencanaan Pembangunan: The Indonesian Journal of Development Planning, 4(2), 191-206.

Sukmadewi, N. P. R. (2021). Storynomics Tourism: Kualitas Wisata Desa Tenganan Pegringsingan. CULTOURE: Culture Tourism and Religion, 2(2), 194-203.

Suyasa, Made. 2020. "Metamorfosis Putri Mandalika: Dari Cerita Rakyat Menjadi Resort Wisata", dalam Novi Anoegrahrajekti, Djoko Saryono, I Nyoman darma Putra (eds) Sastra Pariwisata, pp. 10-27. Yogyakarta: Kanisius.

Wedakarna, Shri I Gusti Ngurah Arya, dkk. 2014. Desa Tua di Bali Utara Kebanggaan identitas Bali Aga (Sidatapa, Cempaga. Tigawasa Pedawa). Denpasar: Fakultas Ilmu Sosial Politik Universitas Mahendradatta Bali.

Widiastini, N. M. A., \& Rahmawati, M. A. P. P. I. (2020, December). Preparing Sidatapa Village as a Bali Aga Tourist Attraction in Buleleng Regency. In 5th International Conference on Tourism, Economics, Accounting, Management and Social Science (TEAMS 2020) (pp. 305-311). Atlantis Press.

Widiastini, N. M. A., Prayudi, M. A., Darmawan, K. K., Andika, K., \& Putra, F. Y. I. K. (2020). Pendampingan Pengemasan Produk Brem Buah Desa Sidatapa, Kabupaten Buleleng. Proceeding Senadimas Undiksha, 1104-1111.

Widiastini, N. M. A., Rahmawati, P. I., Andiani, N. D., \& Parma, I. P. G. (2018). Pengembangan Pariwisata Pedesaan di Kabupaten Buleleng. In Seminar Nasional Riset Inovatif (pp. 372-382).

Widiastini, N. M. A., Rahmawati, P. I., Prayudi, M. A., Dantes, I. G. R., \& Wirasetia, P. A. (2021, November). Preparing Guest Room for Tourists in Sidetapa Village, Buleleng, Bali. In 6th International Conference on Tourism, Economics, Accounting, Management, and Social Science (TEAMS 2021) (pp. 12-21). Atlantis Press.

Widiastini, Ni Made Ary; Rahmawati, Putu Indah; Isti Koma, Fajar Yualida. Ragam Branding Desa dalam Mengembangkan Potensi Wisata Berbasis Budaya Masyarakat di Kabupaten Buleleng. Jurnal Master Pariwisata (JUMPA), [S.l.], p. 195-220, july 2020. 
Wiranatha, AAPA Suryawan et.al. 2021. “Laporan Akhir Kajian Pemulihan Pariwisata Indonesia melalui Pariwisata Berkualitas", Denpasar; Pusat Unggulan Pariwisata Universitas Udayana bekerja sama dengan Kementerian Pariwisata dan Ekonomi Kreatif.

\section{Profil Penulis}

Ida Ayu Laksmita Sari adalah dosen di Program Studi Sarjana Sastra Jepang, Fakultas Ilmu Budaya, Universitas Udayana. Ia menyelesaikan Pendidikan Doktor di Program Studi Doktor Ilmu Linguistik konsentrasi Wacana Sastra, Program Pascasarjana, Universitas Udayana, tamat 2019. Tahun 2021 meraih penghargaan Nusantara Academic Award dari Nusantara Institute sebagai disertasi terbaik bidang budaya. Minat penelitiannya adalah bidang sastra khususnya cerita rakyat Jepang dan kajian komparatif cerita rakyat Jepang dan Bali. Dia mempublikasikan artikel di jurnal internasional bereputasi dan nasional terindeks, beberapa di antaranya adalah “Narrative on Nature Conservation: A Comparative Study of the Folktales of Bali Aga and Ainu” (2020); “Kappa: Makhluk Mitologis Penjaga Sungai dalam Cerita Rakyat Jepang” (2020); dan “Gastronomi dalam Cerita Rakyat Ainu Jepang” (2020).

I Nyoman Darma Putra adalah guru besar Program Studi Sastra Indonesia, Fakultas Ilmu Budaya, Universitas Udayana. Dia menyelesaikan S-1 di Prodi Sastra Indonesia Unud, S-2 di University of Sydney, dan S-3 di University of Queensland. Tahun 20142017, Darma menjadi Ketua Prodi Magister (S-2) Kajian Pariwisata Unud. Selain sudah menulis beberapa buku pariwisata dan biografi tokoh pariwisata Bali, Darma menjadi pemimpin redaksi Jurnal Kajian Bali (terakreditasi Sinta-2) sejak 2011.

Ni Luh Ramaswati Purnawan adalah dosen Prodi Komunikasi, FISIP UNUD Fakultas Ilmu Sosial dan Ilmu Politik (FISIP) Universitas Udayana. Dia menyelesaikan pendidikan doktor di Prodi Doktor Pariwisata Universitas Udayana (2014-2019), sedangkan gelar master di bidnag komunikasi diperoleh dari The Hague University of Applied Sciences, Den Haag (1998 - 1999). Dia sudah mempublikasin beberapa 
Ida Ayu Laksmita Sari, I Nyoman Darma Putra, Ni Luh Ramaswati Purnawan, I Wayan Suardiana

hasil penelitian seperti "Pengembangan Ekowisata Air terjun Singsing Sade di Desa Belimbing Kecamatan Pupuan Kabupaten Tabanan" (Jurnal Udayana Mengabdi, 2018) dan "Paket Wisata Edukasi Subak Upaya Menjaga Keberlanjutan Potensi Pertanian dan Pariwisata berbasis Budaya di Bali" (Kawistara - Jurnal Ilmiah Sosial dan Humaniora, 2017).

I Wayan Suardiana adalah Kordinator Program Studi Bahasa Bali Fakultas Ilmu Budaya Universitas Udayana. Dia menyelesaikan program master di bidang filologi di Universitas Pajajaran Bandung (1999), dan menyelesaikan program doktor di bidang wacana sastra dari Prodi Linguistik Universitas Udayana (2010). Dia menulis buku Crita Manyrita Sajeroning Kasusastran Bali Purwa (Cakra Press, 2011) dan Pantaraning Bali: Wacana-wacana Kritis Indik Budaya Bali (Pustaka Larasan, 2016). 